\title{
EEN HULDE AAN PROF. DR. F. M. TH. DE LIAGRE BÖHL
}

\section{INLEIDINंG DEUR DIE REDAKSIE.}

Op 9 Julie 1953 is a an die Leidse Assiroloog en Oud Testamentikus Prof. Dr. F. M. Th. Böhl'n boekwerk aangebied, wat onder die titel, Opera Minora" 'n keuse uit die verspreide opstelle van die hoogleraar bevat. Die opdrag van die werk is medeonderteken deur twee lede van die redaksie van ons Studies, nl. Prof. Gemser en Prof. Van Selms. Prof. Gemser was persoonlik aanwesig by die plegtigheid, toe in teenwoordigheid van die Nederlandse Minister van Onderwys die sewentigjarige hoogleraar deur sy leerling Prof. Th. C. Vriezen van Groningen toegespreek is. Die Redaksie beskou dit as ' $n$ voorreg om in staat te wees hierdie toespraak en die antwoord van die Jubilaris daarop te publiseer.

Toespraak van Prof. Dr. Th. C. Vriezen bij de overhandiging van de Opera Minora.

Hooggeachte Collega en Mevrouw de Liagre Böhl,

Excellentie,

Hooggeachte vrienden en leerlingen van Prof. de Liagre Böhl,

Het is een lange 70ste verjaardag, die gij viert, Collega de Liagre Böhl, want eigenlijk zijn wij hier om te verrichten wat voor Augustus 1952 bedoeld was, maar toen door omstandigheden van velerlei aard niet kon geschieden.

Het verheugt ons, dat 't mogelijk is, deze samenkomst te hebben, voordat $\mathrm{U}$ een nieuwe jaarkring intreedt en wij niet meer de gedachte zouden kunnen handhaven, dat wij $U$ als 70 -jarige toespreken; het verheugt ons ook, dat 't mogelijk is $U$ nog in de volheid van $U$ w werk te mogen ontmoeten, daar $U$ er als Academisch docent, en als Directeur van het Instituut in functie zijt.

' $k$ Zal niet zeggen, dat de tijd bij de Assyriologie helemaal stil staat, maar in deze wetenschap, waar men nog steeds met eeuwen omgaan kan, alsof het jaren waren (of het recente voorbeeld van Chamurabi's chronologie) behoeft men zich nog niet erg verontrust te gevoelen, als er eens een aantal maanden meer verstrijken dan het oorspronkelijke plan was.

Het is bijzonder jammer - en ik denk, dat het $U$ mèt ons spijt dat deze dag ook al niet helemaal volgens de plannen kan verlopen. doordat hij, die door onze commissie was aangezocht om te spreken. Prof. Gemser van Pretoria, hier niet aanwezig kan zijn, waar hij pas zes dagen geleden van Kaapstad vertrokken, nog op de grote wateren toeft. Zo kan Uw oudste leerling, althans $U_{w}$ eerste gepromoveerde. 
die $U$ het best van ons allen kent en $U$ van het begin van $U w$ loopbaan, nog in Uw eerste Groningse tijd althans, heeft meegemaakt, hier niet zijn.

Toen de hier te lande aanwezige leden van de commissie van oudleerlingen $-U$ heeft $U w$ leerlingen nu eenmaal wel erg verspreid in bijna alle werelddelen zitten, zodat contact met allen niet gemakkelijk is - meenden, dat ik deze middag zou moeten spreken, heb ik mijn aarzelingen overwonnen (ik ben nu eenmaal niet bij $\mathrm{U}$ gepromoveerd en word de Assyriologie steeds meer ontrouw) en deze taak gaarne op mij genomen; want ik gevoel mij altijd nog diep in de schuld bij $U$ voor het vele, dat ik van $U$ mocht ontvangen; gij hebt $U$ w tijd en $U w$ kennis, Uw studeerkamer èn vaak Uw huiskamer met de grootste welwillendheid en gastvrijheid jaren lang voor mij beschikbaar en open gesteld; ' $k$ heb nog wel eens het gevoel, dat ik wel eens erg daarvan heb geprofiteerd in een tijd, toen ik - jaren lang - geregeld $U$ w lessen bezocht. Ik weet trouwens dat dit algemeen erkend wordt door Uw leerlingen, en dat allen zich met dankbaarheid $U w$ tegemoetkomendheid en bereidheid om te geven herinneren en deze hoog blijven waarderen. Het enthousiasme voor $U w$ vak bracht $U$ er toe $U w$ leerlingen met grote gastvrijheid en vaak ongelooflijk veel vertrouwen tegemoet te treden; $k$ ben zelfs overtuigd: wel eens en misschien zelfs wel vaak, met te groot vertrouwen, vooral wat hun capaciteiten en hun zelfwerkzaamheid betrof. $U$ was wel eens te spoedig met jongere-jaars bezig met $z$ ware lectuur en naamt wel eens te gauw de taak van de respondent over, als het niet snel ging, $U$ was nu eenmaal geen schoolmeester, en $U$ zult 't nooit worden. Daardoor kwam er wel eens een mistasten ten aanzien van de werkelijke aanwezige kennis en dit bracht natuurlijk dan uiteindelijk tot wederzijdse teleurstelling. Maar wie mee werkte, kon ontzettend veel leren en kreeg een overzicht over de meest verschillende takken van de Assyriologische wetenschap. U heeft zelf ontzaglijk veel willen omvatten, en ook omvat, en hebt het alles ter beschikking van $\mathrm{Uw}$ leerlingen gesteld.

Een sterke, soms bijna tot in het romantische doorgevoerde, ontdekkingsdrift heeft $U$ zelf bezield - $U$ heeft gestudeerd aan verschillende universiteiten (wat in Duitsland gewoon was) en in twee faculteiten gepromoveerd (wat minder gewoon is), geschiedenis, litteratuur en philologie van het oude Nabije Oosten beoefend in bijna de hele omvang (wij hebben nog wel eens Hethietisch met $U$ gelezen); $U$ heeft oudheden verzameld, waaruit de prachtige collectie de Liagre Böhl, die nu hier in 't Instituut veilig is ondergebracht, behouden voor Nederland; U heeft gereisd naar de landen van het Oosten en daarover interessante brieven geschreven. U heeft opgravingen bezocht, ja zelfs aan opgravingen persoonlijk meegewerkt (we noemen Sichem), $U$ heeft 
texten gelezen van de oude Sumerische tot de latste Babylonische toe, op elk gebied, vanaf het gebied der geschiedenis en de religie tot contracten toe; $U$ heeft mee gewerkt aan ontcijfering van oude schriftsystemen (Sichem-plaquette). $E r$ is bijna geen terrein van Susa tot Gaza, van de boven-Zab tot de wadi el Arisch, waarvoor $U$ geen belangstelling hebt getoond en waarop $U$ niet $U w$ kracht hebt beproefd.

Door dit alles hebt gij Uw leerlingen steeds zeer direct met de belangrijke dingen van het hele Nabij-Oosterse terrein in aanraking kunnen brengen - en hun een kijk gegeven op de samenhang van het leven in de oude Nabij-Oosterse wereld. Gij hebt hun altijd de interessante kant van het vak willen en kunnen laten zien (het nieuwste trok $U$ zelf altijd aan), en hen uit de volheid van $U w$ kennis en ervaring volop doen delen. Uw onbegrensde enthousiasme, dat $U$ zelf meesleepte en op anderen meeslepend werkte, is wel eens de oorzaak geweest, dat leerlingen, die op $\mathrm{U}$ aangewezen waren, enigzins alleen bleven staan. Dit kon bijna niet anders - ook een Nederlandse hoogleraar kan niet alles : field work, research work, tekstpublicaties, college geven, seminaria houden - met promovendi werken, enz. ' $k$ Gevoel zelf het gevaar reeds aankomen, dat men zozeer geboeid is door eigen werk, dat ook volstrekt nodig is, dat men leerlingen niet de leiding geeft, die zij nodig hebben en óók met recht vragen. Er komt bij, dat vele Nederlandse wetenschappelijke onderzoekers niet voldoende geoutilleerd zijn, vooral te weinig medewerkers hebben, om hun krachten te geven aan alles, waaraan zij die moesten geven.

$E r$ is in dit opzicht de laaste jaren veel verbeterd, maar er zijn nog vele wensen te vervullen voor de Nederlandse wetenschappen zich zullen kunnen ontplooien als het gewenst zou zijn.

Uw enthousiasme heeft in Nederland een grote belangstelling gewekt voor het Nabije Oosten. Natuurlijk was hiervoor steeds een bodem, maar gij hebt deze bodem weten te ploegen en te bezaaien. Niet 't minst door Ex Oriente Lux, van $U$ en van Prof. de Buck en hun leerlingen het geesteskind, heeft $U$ in dit opzicht veel bereikt. Ik weet, dat verschillenden tegen dit populariserende werk bezwaren hebben gehad - en ik weet, dat er ook bezwaren tegen zijn, maar ' $k$ meen, dat door E.O.L., en nu door 't Instituut van het Nabije Oosten mede, toch ontzettend veel positief werk is gedaan. Naast de vreugde, die de lezingen en uitgaven bereid hebben aan velen uit universitaire en niet-universitaire kringen, is er een sterkere samenwerking ontstaan tussen de verschillende universiteiten, niet alleen in Nederland, maar ook in België en tussen beide landen onderling. ' $k$ Zeg niet, dat de Benelux uit Ex Oriente Lux is ontstaan en dat ze hetzelfde nastreven, maar Ex Oriente Lux heeft toch wel mogen medewerken op universi- 
tair gebied de gemeenschap van België, en Nederland tot een zekere werkelijkheid te maken.

Uw verdienste als geleerde behoef ik niet breedvoerig uit te meten. Hoe gij gewerkt hebt, daarvan legt de Bibliografie aan 't einde van Uw Opera Minora, die wij U aanbieden kunnen, welsprekend getuigenis af; zowel op 't gebied van het O.T. als op dat van het verdere Oude Oosten, speciaal Mesopotamië, is $U_{w}$ arbeidskracht en belangstelling enorm groot geweest. U stond achter deze studie met de belangstelling van iemand, die met zijn gehele wezen daarbij betrokken was niet alleen door aanleg, niet alleen door omstandigheden ('k denk aan de schitterende traditie, die zich in Weenen in $U w$ jonge jaren begon te vormen), maar ook door diepere motieven: als ik juist zie, kan $U_{w}$ leven alleen als geleerde gezien worden in 't licht van de geweldige spanning tussen een eerbiedwaardige theologische traditie van meer dan een eeuw, die $U$ van huis uit had meegekregen, en een nieuwe seculariserende stroming, die zich omstreeks 1900 breed maakte en zich overwinnaar wist op grond van feiten uit het oude Oosten verkregen: de stenen hadden gesproken, dat in Babel het ware Oosterse licht scheen en de Bijbel een zwakke afglans daarvan was.

$\mathrm{U}$ heeft vastgehouden aan de noodzakelijkheid van het samengaan van de studie der theologische Bijbelwetenschap en der orientalistiek van het Nabije Oosten; U heeft zeer lang, feitelijk $U_{w}$ gehele leven lang, vastgehouden aan de studie van het O.T. naast dié van de Babylonië. Uw leven is steeds in het teken van deze dubbele studie gebleven. al bent $U$ dan van 't begin af in de Litteraire Faculteit terecht gekomen (eerst in Groningen, daarna hier). Uw belangstelling was echter nooit alleen litterair, vooral niet speciaal philologisch of grammatisch, al heeft $U$ ook op dit terrein gewerkt, getuige $U_{w}$,,Sprache der Amarnabriefe"; maar veel meer cultuurhistorisch-phaenomenologisch, tenslotte theologisch. Wij denken aan $U_{w}$ commentaar van Genesis uit $U_{w}$ jongere tijd en de Psalmen van na de tweede wereldoorlog; Uw belangstelling voor Babel was cultuur-historisch maar nog meer godsdiensthistorisch toegespitst en richtte zich bij voorkeur op de verhouding Babel-Bijbel. Het karakter van de studie en de wetenschap is in de loop van de halve eeuw, dat $U$ actief hieraan hebt deel genomen wel zeer veranderd. Niet alleen, dat de centrale plaatsen van deze studie elders kwamen te liggen (in uw jeugd in Weenen, Praag, Duitse universiteiten nu veel meer in de Angelsaksische landen; de oorzaak hiervan ook politiek: als we weer alleen maar de naam Weenen noemen, wat is er dan ontzaglijk veel in Europa in deze eeuw gewijzigd: van hoofstad der Donaustaat, die op de bres lag voor de verdediging van Europa tegen het Oosten, is het een landshoofdstad geworden, 
nu zelfs een bezet gebied); maar ook de belangstelling op Uw studiegebied verschoof zich.

Een sterkere kritische inslag t.a. van stellingen, die een vorige generatie innam, deed zich gevoelen - vooral na de eerste wereldoorlog merkbaar. Men wil geen algemene constructies meer; zelfs die over Babel-Bijbel heeft afgedaan; men wil de feitelijkheid, men wil de zelfstandige culturen, in een woord men wil de zaak i.p.v. het systeem.

Dit is enerzijds een heilzame regressie der wetenschap, teken van herbezinning, anderzijds een blijk ook van moderne zakelijkheid. Dit streven heeft op ons gebied gevoerd tot een nieuwe nog strengere philologische werkmethode, tot verzamelen, classificeren, tot vastleggen i.p.v. tot het geven van beschouwingen. Terecht.

Het onderzoek op 't terrein van de Assyriologie en (na de 2de wereldoorlog ook) van de Sumerologie boekte in de laatste tijd grote vooruitgang en kwam steeds meer op het peil, dat voor waarlijk philologisch werk wordt vereist.

Hier tijdens de algemene herorientering, konden spanningen tussen ouderen en jongeren niet uitblijven, waarbij de ouderen de jongeren al te grote zakelijkheid, al te dorre nuchterheid verweten en de jongeren de ouderen beschuldigden zich al te gemakkelijk systemen op te bouwen en zich daarop vast te leggen. Deze spanning van ouderen en jongeren doet zich ten allen tijde voor en daaraan is (waarom zouden wij 't niet rustig uitspreken) ook Uw studiesector niet geheel ontkomen. Ouderen zullen vaak ' $t$ gevoel hebben, dat ook hiervoor geldt: ,.Es geht einmal vorüber", want elke periode is een stadium; ook ik ben daarvan zeker, zij het ook dat ik volstrekt overtuigd ben, dat hier een noodzakelijk stadium voor de wetenschap moet worden doorgemaakt.

Gij hebt, collega, steeds een buitengewone elasticiteit betoond in Uw wetenschappelijke beoefening, ook al was er wel eens verschil van mening. Dit hebt $U$ gisteren nog getoond bij $U w$ toespraak tot Uw jongste promovendus.

Collega de Liagre Böhl: Gij zijt 40 jaar de bemiddelaar geweest, eerst in Groningen, daarna hier in Leiden bijna 25 jaar, tussen de beschaving en de godsdiensten van de Oud-Oosterse wereld en onze wereld. Gij hebt de banden tussen deze werelden nauw aangehaald en de gedachte sterker gemaakt, dat onze westerse beschaving niet alleen met de Grieks-Romeinse in direct contact stond, maar ook met die van de machtige culturen in het Nabije Oosten.

Wij danken $U$ voor het grote enthousiasme bij ' $t$ onderwijs in de vakken, waaraan gij $U w$ leven hebt verpand, en voor $U w$ onuitputtelijke bereidheid in $U w$ hoogleraarsambt betoond. Wij danken $U$ voor Uw wijsheid, en voor Uw waarlijk goede wil. 
Toen wij ons als Uw leerlingen beraadden, hoe wij U bij Uw heengaan, het meest een genoegen zouden kunnen doen, zijn twee projecten overwogen: een Festschrift, en een bundel Opera Minora. De tijden voor de eerste bleken niet eenvoudig en ook pecuniae causa moet daarvan worden afgezien. Een bundel Opera Minora, waarvoor de firma Welters de uitgave op zich heeft willen nemen en welke zij op zulk een royale wijze heeft willen uitvoeren, is een mogelijkheid gebleken.

Het materiaal moest zeer gezift worden; er was veel te veel copy; gij zelf hebt veel moeten laten vallen, waarvan de opname U dierbaar was geweest; ook de Redactie-commissie heeft soms het snoeimes er in moeten laten zetten. $\mathrm{Z}_{\mathrm{ij}}$ hoopt, dat het boek een werk is geworden, dat niet alleen een welsprekend getuigenis afligt van $U_{w}$ grote werkzaamheid op zo velerlei terrein, maar ook een werk, dat een toekomstig geslacht nog veel zal geven bij haar studie op het terrein van het Nabije Oosten; het moge een boek zijn, waarop $U$ met voldoening neerziet, niet het minst, omdat de verschijning ervan een getuigenis is van de dankbaarheid en hoge waardering, die $U w$ leerlingen $U$ toedragen: wil het aanvaarden als een teken van de goede wil, die gij bij hen hebt gewekt.

Mevrouw Böhl, ook $U$ wensen wij op deze dag van harte geluk met de verschijning van dit boek; ook $U$ willen wij hartelijk danken voor $U_{w}$ medeleven bij zoveel gelegenheden betoond. Moge het $U$ gegeven zijn nog lang naast $U_{w}$ man te staan, die $U_{w}$ aanvulling niet kan missen.

Antwoord van Prof. Dr. F. M. Th. de Liagre Böhl.

Mijn eerste woord is een woord van hartelijke dank aan de vrienden, aanwezigen en die in de verte, die als commissie van redactie het verschijnen van deze kleine geschriften ter hand hebben genomen, aan al de velen, die door hun belangstelling het verschijnen mogelijk hebben gemaakt en aan de uitgever Wolters en aan de directeur van deze vermaarde uitgeverij, waarmee ik van het begin van mijn Groningse tijd af tot heden zo nauw verbonden ben geweest, met Dr. SchepMan, voor alle geduld die betracht werd, voor alle toewijding waarmee het boek werd verzogd.

Speciale en vriendschappelijke dank aan de spreker van zoeven, mijn vriend VRIEZEN, die mij door zijn hartelijkheid verblijdde, maar door de lof die hij mij toezwaaide bijna beschaamde, en aan mijn vriend, Professor BEEK die de zo sympathieke inleiding schreef.

Toen men mij indertijd vroeg wat ik liever wilde: een feestbundel of een verzameling der kleinere geschriften, koos ik het laatste. Was 
in deze keuze allicht een zeker egoisme gelegen, dan ben ik ervoor gestraft : want ik heb hard moeten werken, onmiddelijk beseffende dat het mij onmogelijk zou blijken de stukken - als het ware als een verouderd monument van eigen wetenschappelijke ontwikkeling - ongewijzigd te laten. De wetenschap staat niet stil, en wee de geleerde die stil staat. Deze opera moesten dus, wilden zij de drukinkt die eraan werd besteed waard zijn, bijgewerkt worden. Heden kan ik met goed geweten zeggen: ze zijn bijgewerkt, ze verdienen hun drukinkt en wellicht zelfs het mooie papier en de schitterende band.

Maar nu genoeg over mijzelf en mijn opera. Als ik in deze kring rondkijk, dan vervult mij dankbaarheid nog om een andere reden. Het is de tragiek van de hogere leeftijd, dat zo velen met wie men jong is geweest en die in vreugde en leed gelijke tred met ons hielden, zijn heengegaan. Hierover te klagen of lang uit te wijden zou sentimenteel zijn. Maar als men desondanks nog vast geworteld is in een kring van familie, vrienden, vakgenoten, leerlingen, zoals mij dit te beurt is gevallen en waarvan ik vanmiddag weer de bewijzen mag ondervinden, dan kan men daarvoor niet dankbaar genoeg zijn.

Schopenhauer, die pas als grijsaard in het licht van de publieke belangstelling was komen te staan, heeft zichzelf toen eens bij gelegenheid vergeleken met een toneelspeler die in zijn verstrooidheid op het toneel is blijven staan, terwijl het scherm al weer opengaat voor het volgende bedrijf. Ook in de wetenschap volgen de bedrijven met verschillende bezetting op elkaar, al blijft het stuk dat vertoond wordt hetzelfde. Ik spreek van spel en denk aan HurzingA's boek: „Homo ludens". De bedrijven die gespeeld werden, toen ik mijn loopbaan begon stelden aan de medespeler geheel andere eisen dan die waarmede wij heden bezig zijn. Toen in die lange vreedzame jaren van welvaart vóór de eerste wereldoorlog werden nog alom aangetroffen de laatste uitlopers van het individualisme. Men was nog overtuigd in het laatste stadium te staan van een ontwikkeling die de grenzen en de enkelen hoe langer hoe meer zou doen verdwijnen. Want het vertrouwen op de geleidelijkheid en de veiligheid der uitkomst speelde toen de hoofdrol. Thans, heden ten dage worden alom aangetroffen de innerlijke en uiterlijke hoge scheidsmuren tussen de rassen en volken, de groepen en vakken, waarvan wij ons het verdwijnen, als wij eerlijk zijn, eigenlijk nog slechts katastrofaal, door een plotselinge omkering kunnen voorstellen.

En van de wetenschap, tenminste van onze tak van de wetenschap, gold en geldt feitelijk hetzelfde. Toen, in die jaren kort na 1900, waren er wel verwoede specialisten, maar eigenlijk geen vaste grenzen tussen de verschillende takken der historische wetenschap: men abstraheerde, men vergeleek, men trok parallelen, men berekende de hoofdsom uit 
de meest uiteenlopende elementen. Op godsdiensthistorisch terrein is Frazer met zijn Golden Bough het wellicht voor de jongeren ook nog steeds best bekende voorbeeld.

En heden? Ja zeker, evenals er toen verwoede specialisten waren, zijn er heden nog constructeurs à la Toynbee, maar hun constructies worden niet meer tot stand gebracht door de intuitie van enkelen, maar door het teamwork van velen. En verder: de scheidsmuren, de „Eigenbegrifflichkeit" (sit venia verbo), het ijverige verzamelen van materiaal binnen de verschillende schotten en schotjes; maar feitelijk heerst er al vrees voor voorbarige gevolgtrekkingen en schroom boven en buiten de muren uit te kijken.

Is dat een verarming? Was het oude beter? Spreekt hier de oude, die terugverlangt naar de dagen en methoden van zijn jeugd? Met nadruk zou ik deze vraag ontkennend willen beantwoorden. Want het oude met zijn lichtzinnig overschrijden der grenzen was verkeerd, en het nieuwe met zijn voorzichtiger bepalingen en beperkingen is nodig. Op het terrein van het oude Nabije Oosten is dit alles ook nog om andere redenen duidelijk. Toen opende zich voor de historicus, ook voor de godsdiensthistoricus, opeens een ruim verschiet; onbeperkt meende men veral te mogen wandelen, nergens stond er ..verboden toegang"; hoe geaccidenteerd, hoe door en door verschillend het nieuwe terrein was, besefte men pas later.

Maar de bergen en scheidsmuren behoren nog niet tot het laatste bedrijf. Ze zijn nodig. Ook in het volgende bedrijf, dat straks aanbreekt, zullen zij er zijn en blijven: tussen de takken van wetenschap evenals tussen de volken. Maar er zullen deuren zijn en ramen en straten en bruggen. Niet sloping of verflauwing der grenzen is ons ideaal, maar samenwerking in het streven naar een hogere eenheid. Op 't ogenblik worden de instrumenten nog gestemd, en wat wij horen is niet altijd harmonieus. Maar straks zal de symphonie weerklinken, straks beluisteren we het volle orkest. Willen wij dit bereiken, dan is onze vrijwillige beperking niets dan zelfbedwang, noodzakelijke zelfbeheersing. Niet als ,laudator temporis acti", maar als "laudator temporis futuri" zou ik hier willen optreden. Want al wat leeft, leeft in de toekomst.

Dit is geen - nog geen - afscheidscollege. Dat ik mijn academische taak nog een jaar langer dan de fatale leeftijd, die de hoogleraar bij de wet tot aftreden noopt, heb mogen verrichten: dat was wel de grootste vreugde, die mij kon zijn beschoren. Toch is er onwillekeurig reeds vanmiddag een zekere afscheidsstemming. Afscheid ... maar dan toch niet geheel en al in de zin en de geest van het vers, dat ik aanhaal in de taal, die mij dierbaar is gebleven: 
..Wenn ich Abschied nehme, will ich leise gehn, Keine Hand mehr drücken, nimmer rückwärts sehn. In dem lauten Saale denkt mir keiner nach, Dankt mir keine Seele, was die meine sprach.

Morgendämmerung weht mir draussen um das Haupt, Und sie kommt, die Sonne, der ich doch geglaubt. Lärmt bei euren Lampen und vergesst mich schnell! Lösche meine Lampe! - Bald ist alles hell!"

Dit vers van een weinig bekende Duitse dichter (Katl Weit brecht) is mooi, tot op zekere hoogte zelfs ontroerend. Toch zou ik het nu ik zelf afscheid neem, niet zonder meer willen overnemen. Zeker de strekking lijkt bijna bovenmenselijk: eigen persoon uit te schakelen op het moment van het afscheid. Maar bedoelt de dichter met zijn gebrek aan godsdienstige klank dit eigenlijk wel eerlijk? Niet minder dan twee keer herhaalt hij direct in de eerste regel het woorde ,ik". En dit ,ik", deze concentratie op eigen persoon, blijft hem in de weg staan, zelfs waar hij zijn vrienden vraagt hem spoedig te vergeten. Maar niet op hèm komt het aan, maar op hetgeen hij achterlaat: zijn taak, zijn werk.

Dan heeft de dichter van het oude Babylonische Gilgamesj epos dit punt, waar het op aankomt, toch nog beter begrepen. Gilgamesj. de oude held, heeft na oneindige inspanning alle kans op onsterfelijkheid verkeken, het kruid des levens is voor hem verloren, hij beseft de vergankelijkheid en is de wanhoop nabij. Daar troost hem het gezicht op het werk, dat hij gewrocht heeft, de muur van zijn stad Uruk die hij bouwde. En hij spreekt tot zijn makker :

„Klim op, Ur-sanabi, en wandel op de muur van Uruk,

Vors uit de onderbouw, bekijk het tichelwerk:

Of haar tichelwerk niet van baksteen is,

En of haar grondslag niet gelegd hebben de zeven wijzen! ...

De mensen zijn sterfelijk, het werk hunner handen, dat zij voor de gemeenschap hebben gewrocht, trotseert de tijd en vestigt hun roem tot in lengte van dagen. Dat is voor deze dichter van het oude Babylonische epos de slotsom der wijsheid.

En toch: ik heb deze muur van Uruk, die toen voor de eeuwigheid gebouwd scheen, gezien. Dat wil zeggen: ik zag geen muur, maar onduidelijke sporen in het zand, op grond waarvan onze archaeologen de oude loop van de verdwenen muur met behulp van opgravingen menen te kunnen gaan. Wie dat ziet, wordt bescheiden. 
Een muur is dood. Onvergankelijk - voor zover dan iets hier op aarde onvergankelijk mag beten - zijn slechts het leven en de geest. De enkele sterft, dit blijft, met alle invloeden en indrukken, die de enkele, hoe bescheiden dan ook, heeft kunnen nalaten. Dat geldt niet alleen van het gezin met zijn geestelijke erfenis en zijn tradities; dat geldt ook van de wetenschap. De fakkel wordt niet uitgeblust, maar doorgegeven, door anderen overgenomen en op hun beurt verder gegeven. Wij allen zijn of behoren te zijn „Quasi cursores vitae lampada tradunt". De oude fakkeldans is wel een der diepste levenssymbolen. Wat blijft, zijn levende mensen: de kring van vrienden, leerlingen en vertrouwden, die niet geleerd hebben het ,jurare in verba magistri", maar die in telkens herhaalde hernieuwing het oude licht doorgeven aan de komende geslachten.

In deze geest zou ik u, mijn vrienden, in gedachten de hand willen drukken en $u$ voor deze middag van harte willen danken.

Leiden, 9 Juli 1953. 